\title{
National Cancer Survivor Day: Guest Comment
}

\section{Dr. Saransh Srivastava ic}

National Cancer Survivors Day is an annual observance held on the first Sunday in June every year. "It is a celebration for those who have survived, an inspiration for those recently diagnosed, a gathering of support for families and an outreach to the community". According to the National Cancer Institute (NCI), "a person is considered to be a survivor from the time of diagnosis until the end of life". ${ }^{1}$ With nearly 14 million cancer survivors in the United States and over 1.5 million new cases diagnosed each year, cancer continues to affect almost every American, whether through a family member or through their own experience (CDC \& NCI, 2015).

The American Cancer Society estimates that more than 16.9 million Americans with a history of cancer were alive on January 2019. Some of these people were cancer-free, while others still had signs of cancer and may have been undergoing treatment. It is estimated that there will be about $1,806,590$ new cancer cases diagnosed in 2020. This number does not include basal and squamous cell skin cancers.

\section{Cancer Survivorship ${ }^{2}$}

As difficult as treatment is, thousands of cancer survivors have said that the experience led them to make important changes in their lives. Taking the time to appreciate each new day, learning to take better care of themselves, learning the value of how others care for them, or becoming national advocates for better cancer research, treatment, and care were some of these significant changes.

The National Cancer Institute has developed a booklet called Facing Forward: Life After Cancer Treatment. The information in this booklet is designed mainly for cancer survivors who have recently completed their cancer treatment, but you may find the information helpful even if you were treated a long time ago. Its purpose is to give cancer survivors and their loved ones a better idea of what to expect after treatment ends. It covers what may happen with:
- Your medical care

- Your body

- Your mind and your feelings

- Your social relationships

- Practical matters such as job and insurance issues

\section{The Cancer Survivors' Bill of Rights ${ }^{2}$}

The National Coalition for Cancer Survivorship presents this new version of the Survivors' Bill of Rights to call public attention to survivor needs, to enhance the quality of cancer care, to empower cancer survivors, and at the same time bring greater satisfaction to them and their physicians, employers, families, and friends.

1. Survivors have the right to continuous lifelong medical care, as needed. The physicians and other professionals involved should make every effort to be:

- Sensitive to cancer survivors' lifestyle choices and their need for self-esteem, dignity and privacy of the information trusted to them;

- Careful, no matter how long these patients have survived, to take symptoms seriously and not to dismiss aches and pains, for fear of recurrence is a normal part of survivorship;

- Vigilant to watch for any long-term and late effects of cancer and its treatment in follow-up clinics and offices;

- Informative and open, providing survivors with as much or as little candid medical information as they wish, and encouraging informed participation but not expecting survivors to manage that care on their own;

- Knowledgeable about counseling and rehabilitation resources, and willing to refer survivors and their families as appropriate for emotional support and therapy aiming to improve the texture as well as the quantity of time that is theirs to live.

2. No matter in which setting their care is offered--be it fee-for-service or some sort of managed care system--survivors have the right to quality care emphasizing: 
- Informed choice--choice of the setting in which care is delivered, choice of primary physicians and specialists delivering that care, as well as choice of appropriate, effective and safe treatments (including ongoing clinical trials);

- Efficient yet humane management of such unfortunate by-products of disease as fatigue and pain--pain control management, for example, which approaches survivors more as partners in identifying the proper amount of medication needed at any given time than as potential drug addicts;

- Appropriate use of hospital and other facilities, wherein cost effectiveness and patient-centered care are balanced so that no survivor is dismissed--after a mastectomy, for example--unable to care for her or himself or secure the care needed to avoid dangerous and painful situations;

- Constant respect for survivors' wishes as to when and how to discontinue treatment should that time arise, including the scrupulous honoring of "living wills" and similar documents.

3. In their personal lives, survivors, like other Americans, have the right to the pursuit of happiness. This means they have the right:

- To talk with their families and friends about their cancer experience if they wish, but to refuse to discuss it if that is their choice, and not to be expected to be more upbeat or less blue than anyone else;

- To be free of the stigma of cancer as a "dread disease" in all social relations, wherever they may take place-from home to work or market-place;

- To be free of blame for having the disease and of guilt for having survived it;

- To participate in support groups and other survivor support and/or advocacy activities as they wish, for in such settings they usually feel less isolated, more informed, and more able to express their feelings, be they feelings of hope or of despair, without fear of being regarded as "bad" or "ungrateful" or simply "uncooperative" patients.

4. In the work place, survivors have the right to equal job opportunities. This means they have the right:

- To aspire to jobs worthy of their skills, and for which they are trained and experienced, and thus not to have to accept jobs they would not have considered before their cancer experience;

- To be hired, promoted, and accepted on return to work, according to their individual abilities and qualifications, and not according to "cancer" or "disability" stereotypes with "reasonable accommodation," under federal and state law, such as changes in duties or hours, which allows them to work while receiving medical treatment without falling into a survivors' "Catch-22"--too ill to work, but too healthy to qualify as "disabled" and so entitled to protection under the Americans with Disabilities Act;

- To maintain privacy about their medical histories.

5. Since health insurance is an urgent survivorship concern, every effort should be made to assure all survivors decent affordable coverage, whether public or private, or provided under managed care or feefor-service systems. This means:

- For employers, that survivors have the right to be included in group health coverage regardless of health history;

- For physicians, counselors, and other professionals concerned, that they keep themselves and their survivor-clients informed and up-to-date on the dangers of health insurance discrimination.

6. For social policy makers, both in government and in the private sector, that they seek both to broaden insurance programs to include diagnostic procedures and treatments which help prevent recurrence and ease survivor anxiety and pain, as well as to lower the unfair barriers often imposed by the accidents of race, minority culture, age, or plain lack of means to pay for adequate health insurance coverage.

In the end, I would like to thank the entire editorial team of IHRJ for providing me a platform to pen my thoughts on the important occasion of National cancer survivor's day. 


\section{Cite this article as:}

Srivastava S. National Cancer Survivor Day: Guest Comment. Int Healthc Res J. 2020;4(3):49-51. https://doi.org/10.26440/IHRJ/0403.06348

\section{AUTHOR AFFILIATIONS AND CORRESPONDING ADDRESS:}

Assistant Professor, Department of Periodontics, School of Dental Sciences, Sharda University (ORCID: https://orcid.org/oooo-ooo1-7708-4749)

e-mail id for correspondence: saransh.1[at]sharda[dot]ac[dot]in 